November 2020

\title{
ANALISIS BAHASA PERSUASIF PADA IKLAN PROMOSI DI KOTA PERBAUNGAN
}

\author{
Dina Novita ${ }^{1^{*}}$ \\ Joko Hariadi ${ }^{2}$ \\ Muhammad Taufik Hidayat ${ }^{3}$ \\ ${ }^{1}$ Program Studi Bahasa Indonesia, FKIP Universitas Samudra \\ ${ }^{2}$ Program Studi Bahasa Indonesia, FKIP Universitas Samudra \\ ${ }^{1}$ Program Studi Bahasa Indonesia, FKIP Universitas Samudra \\ *dinanovita109@gmail.com
}

\begin{abstract}
This research is entitled "Analysis of persuasive language on promotional advertisements in the city of Perbaungan". The formulation of the problem in this study is to analyze the persuasive language contained in promotional advertisements in the city of Perbaungan. This study also aims to describe persuasive communication techniques contained in promotional advertisements in the city of Perbaungan. The research method used in this study is a qualitative descriptive method. The subject of this research is the use of persuasive language in promotional advertisements in the city of Perbaungan. The research instrument is the researcher himself (human instrument). The data collection technique used the observation, method various, listening techniques and note-taking techniques. The results of the research are (1) association techniques in persuasive language in promotional advertisements in the city of Perbaungan found one sample of association techniques. (2) reward techniques (payoff technique) in persuasive language in promotional advertisements in the city of Perbaungan foun eleven samples of reward tecniques (payoff technique). (3) arrangement techniques (icing technique) in persuasive language in promotional advertisements in the city of perbaungan found thirteen samples of arrangement techniques (icing technique). The persuasive communication techniques that are most commonly found in research are organizational techniques (icing technique). Furthemore, the techniques that were not found were two techniques, namely (1) integration technique and (2) red-herring technique.
\end{abstract}

Keywords:

Persuasive Language, Promotional Advertisement, Perbaungan

\begin{abstract}
Abstrak
Penelitian ini berjudul "Analisis Bahasa Persuasif Pada Iklan Promosi di Kota Perbaungan". Rumusan masalah dalam penelitian ini adalah untuk menganalisis bahasa persuasif yang terdapat pada iklan promosi di Kota Perbaungan. Penelitian ini juga bertujuan untuk mendeskripsikan teknikteknik komunikasi persuasif yang terdapat pada iklan promosi di Kota Perbaungan. Metode penelitian yang digunakan dalam penelitian ini adalah metode deskriptif kualitatif. Subjek penelitian ini yaitu penggunaan bahasa persuasif pada iklan promosi di Kota Perbaungan. Instrumen penelitiannya yaitu peneliti sendiri (human instrument). Teknik pengumpulan data menggunakan metode observasi, teknik rekam, teknik simak dan teknik catat. Analisis data menggunakan metode deskriptif kualitatif. Hasil dari penelitian yaitu (1) teknik asosiasi dalam bahasa persuasif pada iklan promosi di Kota Perbaungan ditemukan satu sampel teknik asosiasi, (2) teknik ganjaran (payoff technique) dalam bahasa persuasif pada iklan promosi di Kota Perbaungan ditemukan sebelas sampel teknik ganjaran (payoff technique), (3) teknik tataan (icing technique) ) dalam bahasa persuasif pada iklan promosi di Kota Perbaungan ditemukan tiga belas sampel teknik tataan(icing technique) ). Teknik-teknik komunikasi persuasif yang paling banyak ditemukan dalam penelitian ini yaitu teknik tataan(icing
\end{abstract}


Jurnal Samudra Bahasa

p-ISSN 2716-3113

Volume 4 Nomor 2

e-ISSN 2715-7245

November 2020

technique) ). Selanjutnya, teknik yang tidak ditemukan berjumlah dua teknik yaitu (1) teknik integrasi dan (2) teknik red-herring.

\section{Kata Kunci:}

Bahasa Persuasif, Iklan Promosi, Perbaungan 


\section{Pendahuluan}

Manusia sebagai makhluk sosial membutuhkan interaksi dan komunikasi. Hal tersebut membuat manusia membutuhkan media untuk berinteraksi salah satunya adalah bahasa. Bahasa digunakan oleh masyarakat untuk berkomunikasi dengan masyarakat lainnya, seperti menyampaikan informasi, pesan, mengungkapkan perasaan, keinginan, dan lain sebagainya.

Persuasif merupakan kata kerja dari persuasi yang artinya bahasa yang digunakan untuk mempengaruhi serta dapat meyakinkan banyak orang. Pada prinsipnya persuasi merupakan upaya menyampaikan informasi dan interaksi antar satu sama lain dengan kondisi yang mampu memahami sekaligus sepakat untuk melakukan sesuatu yang memiliki kepentingan bagi mereka. Menurut Kamus Besar Bahasa Indonesia (2012:1062) " Persuasif memiliki sifat membujuk secara perlahan supaya menjadi yakin, sehingga seseorang akan mudah terpengaruh dengan informasi yang didapatkan." Senada dengan hal itu, Roekomy (dalam Astuti, 2017:39) "Persuasi adalah suatu kegiatan psikologis dalam usaha memengaruhi pendapat, sikap, dan tingkah laku seseorang untuk berpendapat, bersikap, dan bertingkah laku seperti yang diharapkan." Usaha melakukan persuasi ini memusatkan perhatian pada upaya mengubah atau memperkuat sikap atau kepercayaan khalayak dengan tujuan mengajak mereka bertindak dengan cara tertentu De Vito (dalam Syamsurizal, 2016:129). Dengan berkomunikasi antar sesama, setiap orang berharap informasi yang disampaikan dapat dimengerti dan dipahami. Mulyawan (dalam Damayanti, 2016:78) berpendapat bahwa "Iklan merupakan sebuah produk komunikasi yang bertujuan untuk mempromosikan penjualan sebuah produk barang atau jasa, dapat memengaruhi opini masyarakat, mendapatkan dukungan politik, dan menyebarluaskan sesuatu hal untuk mencari informasi sesuai dengan keinginan." Senada dengan hal itu, kasali (dalam Damayanti, 2016:74) mengatakan bahwa "Iklan adalah pesan yang menawarkan suatu produk yang ditunjukkan masyarakat melalui media.

Promosi adalah perkenalan dalam rangka memajukan usaha dagang yang dilakukan secara terus menerus (KBBI, 2012:1104)."Promosi merupakan salah satu cara dalam menyampaikan informasi terbaru dengan berbagai ide penyampaian agar pembaca atau pendengar tertarik untuk melihatnya. "Promosi berupaya untuk merangsang coba-coba dari konsumen, meningkatkan permintaan dari konsumen dan memperbaiki kualitas produk. Dengan adanya promosi, rasa ingin tahu calon konsumen akan muncul untuk mengetahui informasi baru tersebut.

Adapun alasan peneliti mengambil analisis bahasa persuasif pada iklan promosi di Kota Perbaungan, yaitu: (1) Bahasa persuasif merupakan bahasa yang sering digunakan penjual agar pembeli tertarik untuk membeli produk yang ditawarkan; (2) Dalam iklan promosi banyak menggunakan bahasa persuasif yang beragam untuk mempermudah dalam proses penjualan produk;(3) Di Kota Perbaungan terdapat banyak pedagang yang menjual berbagai macam produk yang berasal dari berbagai daerah, kalangan, dan suku. Dari beberapa alasan yang telah disebutkan, maka peneliti tertarik untuk menganalisis bahasa persuasif pada iklan promosi di Kota Perbaungan.

Penelitian tentang bahasa persuasif sudah banyak dilakukan oleh peneliti sebelumnya. Namun, penelitian bahasa persuasif pada iklan promosi di Kota Perbaungan belum pernah dilakukan. Penelitian yang telah dilakukan oleh peneliti mengenai bahasa persuasif seperti Harista (2017) "Melakukan penelitian dengan judul Penggunaan Bahasa Persuasi di Media Social dalam Berdakwah Pada Akun Facebook'yusuf Mansur (Official)'adapun kesimpulan dari penelitian tersebut ialah untuk mengetahui sejauh mana penggunaan bahasa persuasi yang dipakai oleh Ustaz Yusuf Mansur dalam berdakwah secara tertulis pada akun resminya 'Yusuf Mansur (official)' di media sosial Facebook. Senada dengan itu, Wati (2017) meneliti 
tentang Kemampuan Komunikasi Persuasif Pengelola Museum Provinsi Sulawesi Tengah hasil penelitian ini dilakukan berdasarkan 3 tahapan yaitu ethos, pathos, dan logos. penelitian ini hanya fokus pada bagaimana komunikasi persuasif yang digunakan oleh pengelola Museum Provinsi Sulawesi Tengah kepada masyarakat yang berkunjung. Komunikasi persuasif penting dilakukan terutama pada iklan promosi karena dengan menggunakan komunikasi persuasi berarti pedagang tersebut sudah memberikan kesan yang positif bagi calon konsumen yang datang. Dengan adanya bahasa persuasif , para pengunjung maupun pembeli akan lebih tertarik untuk melihatnya.

\section{Metodogi Penelitian}

Penelitian ini merupakan penelitian kualitatif dengan metode deskriptif. Metode Deskriptifkualitatif ini menggunakan objek penelitian, menguraikan dan menganalisis unsur-unsur yang terdapat pada objek penelitian. Sugiyono (dalam Azwardi, 2018:240) menyatakan bahwa penelitian kualitatif merupakan sebuah penelitian pada kondisi yang alamiah, langsung ke sumber data, dan peneliti adalah instrumen kunci pada penelitian tersebut.Penelitian kualitatif lebih bersifat deskriptif sehingga data yang terkumpul berbentuk kata-kata atau gambar, bukanberupa angka.Penelitian deskriptif bertujuan membuat deskripsi, gambarangambaran atau lukisan secara sistematik, faktual, akurat mengenai fakta-fakta, sifatsifat, serta hubungan antar fenomena yang diselidiki Nazir (dalam Azwardi, 2018:241). Lofland dan Lofland (dalam Moleong, 2017:157) Sumber data utama dalam penelitian kualitatif adalah kata-kata, serta tindakan, sedangkan selebihnya adalah tambahan seperti dokumen dan lainlain.Sumber data dalam penelitian ini yaitu masyarakat di Kota Perbaungan. Data penelitian ini berupa tuturan yang mengandung bahasa persuasif yang dipakai atau dihasilkan pada iklan promosi di Kota Perbaungan saat menawarkan barang dagangan. Teknik pengumpulan data yang digunakan dalam penelitian ini yaitu: teknik rekam, teknik simak, dan teknik catat.

\section{Hasil dan Pembahasan}

Pada bagian ini peneliti mendeskripsikan dan menganalisis hasil penelitian yang telah diperoleh. Data penelitian ini diperoleh dari hasil komunikasi yang dilakukan oleh pedagang dalam meyakinkan calon pembeli di Kota Perbaungan. Data penelitian ini merupakan hasil dari pengamatan peneliti tentang bahasa persuasif yang digunakan oleh pedagang di Kota Perbaungan. Data dikumpulkan dengan menggunakan observasi, teknik rekam, teknik simak dan teknik catat. Penggunaan bahasa persuasif tidak lepas dari interaksi yang beragam. Peneliti menemukan bahwa terdapat beberapa variasi bahasa persuasif yang digunakan oleh pedagang di Kota Perbaungan. Hasil penelitian ini merupakan data lisan berupa percakapan yang diperoleh dari tuturan pedagang yang terdapat di Kota Perbaungan.

Penelitian ini menggunakan pendekatan kualitatif untuk menganalisis bahasa persuasif pada iklan promosi di Kota Perbaungan. Jumlah data yang diambil dalam penelitian ini terdiri dari empat belas sampel pedagang yang melakukan promosi di Kota Perbaungan. Mereka berdagang di lokasi dan waktu yang berbeda. Pada proses pengklasifikasian penelitian ini, terdapat dua cara promosi penjualan yaitu luar jaringan (offline) dan dalam jaringan (online).

Berdasarkan data yang telah diperoleh, ditemukan penggunaan persuasif dalam bahasa yang dituturkan oleh responden sebagai pedagang di Kota Perbaungan. Data tersebut selanjutnya dianalisis berdasarkan teknik persuasif yang ditinjau dari teknikteknik persuasif. Penyajian analisis data dilakukan dengan menampilkan data teks yang terkait dengan bagian yang dianalisis selanjutnya disajikan analisis data yang ditampilkan dengan contoh data dan diberi kode berdasarkan urutan nomor data, serta menganalisis data sesuai dengan landasan 
teoretis. Berikut ini disajikan data-data dan selanjutnya dianalisis:

Bentuk Teknik-teknik Komunikasi Persuasifadalah sebagai berikut: Teknik asosiasi, teknik integrasi, teknik ganjaran (payoff technique), teknik tataan(icing technique), teknik red-herring.

Nama Toko : Sahabat Ponsel

Hari /Tanggal : Jumat, 13 November 2020

Pukul : 16.13 WIB

\section{Bentuk Persuasif}

\section{Penjual :}

"kembali lagi kita ingatin untuk seluruh masyarakat Perbaungan cari smart phone nya langsung aja datang ke Sahabat Ponsel Perbaungan, karena kita lagi ngadain promo besar-besaran dan disetiap pembelian hand phone kamu berhak membawa hadiah menarik dari Sahabat Ponsel, bukan hanya smart phone nya kita hadirin juga smart watch tv nya dan buat kamu yang mau cari aksesoris HP nya tersedia lengkap di Sahabat Ponsel. Jadi, buruan langsung aja datang ke Sahabat Ponsel atau kamu bisa aja langsung cek instagram @Sahabat_Ponsel88. Singgah kak, kita lagi promo, singgah hand phone nya lagi promo, singgah kak."

Persuasif pada iklan promosi di Kota Perbaungan dilihat dari teknik-teknik komunikasi persuasif menggunakan teknik tataan (icing technique) dalam ujaran "kembali lagi kita ingatin untuk seluruh masyarakat Perbaungan cari smart phone nya langsung aja datang ke Sahabat Ponsel Perbaungan." responden berusaha menarik perhatian partisipan untuk mampir mengunjungi lokasi penjualan karena pada saat itu responden baru saja memulai kegiatan penjualan. Lokasi penjualan masih sepi, belum ada partisipan yang mampir. Teknik ganjaran(payoff technique) juga terdapat dalam ujaran responden "karena kita lagi ngadain promo besar-besaran dan disetiap pembelian hand phone kamu berhak membawa hadiah menarik dari Sahabat Ponsel." ia berusaha mempengaruhi partisipan dengan mengiming-ngimingi hal yang menguntungkan atau hal yang menjanjikan harapan.

Nama Toko : Habibie Parfume

Hari / Tanggal : Senin, 14 Desember 2020

Pukul : 12:59 WIB

\section{Bentuk Persuasif}

Penjual : "ada."

Pembeli : "aroma lain ada kak?."

Penjual : "bentar ya kak, ini orang sering make kak."

Pembeli : "apa itu kak?."

Penjual : "coba disemprotkan dulu."

Pembeli : "yang pertama aja tadi kak."

Penjual : "yang pertama mau berapa $m l$ ?."

Pembeli : "ukuran botolnya berapa kak? Ini gak bawa botol berarti harganya yang ini ya kak."

Penjual : "iya kak, ini yang harganya sama botol kak."

Pembeli : "yang $15 \mathrm{ml}$ aja."

Penjual : "dosisnya 0,5 ya kak."

Pembeli : "iya, ini parfum apa kak?."

Penjual : "itu parfum laundry kak. Ambillah kak, untuk gosok."

Pembeli : "wanginya enak-enak gak kak?."

Penjual : "ini contohnya kak."

Pembeli : "biasa orang beli pake yang mana?."

Penjual : "yang merah sih biasanya, ambillah kak satu sepuluh ribunya kak."

Pembeli : "yaudah, yang warna merahlah satu. Berapa kak?."

Penjual : "jadinya $30+17=47$. Oh iya kak, kami lagi ngadain voucher kak."

Pembeli : "apa tu kak?." 


\begin{tabular}{|c|c|}
\hline Penjual & $\begin{array}{c}\text { "yang merah sih biasanya, } \\
\text { ambillah kak satu sepuluh } \\
\text { ribunya kak." }\end{array}$ \\
\hline Penjual & $\begin{array}{l}\text { :"kalo misalnya kakak beli } \\
\text { parfum. Beli satu gratis satu. } \\
\text { Misalnya kek yang kakak beli } \\
\text { tadi kan } 15 \mathrm{ml} \text { jadi gratisannya } \\
15 \mathrm{ml} \text { juga kek gitu. Jangan } \\
\text { lupa ya kak, promonya tinggal } \\
\text { sebentar lagi." }\end{array}$ \\
\hline
\end{tabular}

Pembeli : "jadi nanti kalau mau beli dibawa gitu?."

\begin{tabular}{|c|c|}
\hline Penjual & :"iya." \\
\hline embeli & : "jadi berapa kak?.” \\
\hline & $\begin{array}{l}\text { : “47 kak, premiumnya gak } \\
\text { kak?.” }\end{array}$ \\
\hline Penjual & $\begin{array}{l}\text { :"kalo misalnya kakak } \\
\text { parfum. Beli satu gratis s } \\
\text { Misalnya kek yang kakak } \\
\text { tadi kan } 15 \mathrm{ml} \text { jadi gratisan } \\
15 \mathrm{ml} \text { juga kek gitu. Jan } \\
\text { lupa ya kak, promonya ting } \\
\text { sebentar lagi.” }\end{array}$ \\
\hline Pembeli & $\begin{array}{l}\text { : "yang premiumnya gaklah, } \\
\text { yang ini aja." }\end{array}$ \\
\hline enjua & :"makasih ya kak." \\
\hline
\end{tabular}

Persuasif pada iklan promosi di Kota Perbaungan dilihat dari teknik-teknik komunikasi persuasif terdapat tiga teknik asosiasi dalam ujaran seperti pada (1) "bentar ya kak, ini orang sering make kak." (2) "itu parfum laundry kak. Ambillah kak, untuk gosok." (3) "yang merah sih biasanya, ambillah kak satu sepuluh ribunya kak." Responden bermaksud menarik perhatian partisipan dengan menawarkan produk yang sering digunakan banyak orang dengan harga yang pantas bagi mereka. Teknik ganjaran(payoff technique)terdapat dalam ujaran responden "kalo misalnya kakak beli parfum. Beli satu gratis satu. Misalnya kek yang kakak beli tadi kan $15 \mathrm{ml}$ jadi gratisannya $15 \mathrm{ml}$ juga kek gitu." Responden berusaha mempengaruhi partisipan dengan mengiming-ngimingi hal yang menguntungkan atau hal yang menjanjikan harapan. Teknik tataan (icing technique) jugaterdapat dalam ujaran "Jangan lupa ya kak, promonya tinggal sebentar lagi." Responden memberitahukan bahwa penawaran dengan waktu yang terbatas. Agar partisipan datang kembali sesuai waktu yang ditentukan.

\section{Nama Toko : My Poot Street Food \\ Hari/ Tanggal : Rabu, 16 Desember 2020 \\ Pukul : 17:57 WIB}

\section{Bentuk Persuasif}

\begin{tabular}{|c|c|}
\hline Penjual & : "singgah." \\
\hline Pembeli & : "kebabnya satu bang." \\
\hline Penjual & $\begin{array}{l}\text { : "gak beli dua sekalian } \\
\text { bang, beli dua gratis satu." }\end{array}$ \\
\hline Pembeli & $\begin{array}{l}\text { : "gak dulu bang." murah } \\
\text { hari ini." }\end{array}$ \\
\hline Pembeli & $\begin{array}{l}\text { : "oke, nanti aja bang, } \\
\text { berapa bang?." }\end{array}$ \\
\hline Pembel & $\begin{array}{l}\text { : "sepuluh aja, makasih ya } \\
\text { bang." }\end{array}$ \\
\hline
\end{tabular}

Persuasif pada iklan promosi di Kota Perbaungan dilihat dari teknik-teknik komunikasi persuasif menggunakan teknik ganjaran(payoff technique) dalam ujaran responden "gak beli dua sekalian bang, beli dua gratis satu." Ujaran bermaksud untuk mengiming-ngimingi partisipan hal yang menguntungkan atau yang menjanjikan harapan. Teknik tataan (icing technique) juga terdapat dalam ujaran "dua ajalah bang, kita lagi promo murah hari ini." Ujaran tersebut mengandung pesan meyakinkan partisipan agar tertarik dengan tawaran yang dimaksud. Nama Toko : Bintang Ponsel

Hari / Tanggal : Jumat, 13 November 2020

Pukul : 17:32 WIB

\section{Bentuk Persuasif}

Cowok : "yuk, yuk buruan langsung belanja $H p$-nya di store kita. Kenapa? Karena disetiap pembelian Hp android bakal dapat voucherluckydraw, 
Cewek

Cowok

\section{Cewek : "ha biar tau kelen di sini banyakkan promonya?."}

Cowok : "iya promonya $t u$ gakhalu-halu bentuknya itu nyata banget. Jadi, buruan aja yang cari hand phone langsung aja ke store kita. Dimana store nya?."

Cewek : "di B store dan Bintang Ponsel."

Persuasif pada iklan promosi di Kota Perbaungan dilihat dari teknik-teknik komunikasi persuasif menggunakan teknik tataan(icing technique) dalam ujaran " $y u k$, yuk buruan langsung belanja Hpnya di store kita. Kenapa? Karena disetiap pembelian $H p$ android bakal dapat voucherluckydraw, voucher undian, dan promo-promo tak terduga seperti potongan harga dan lain-lain. Jadi, langsung aja cus beli hand phone nya di store kita aja, di Bintang Ponsel store Perbaungan." Ujaran responden mengandung pesan yang bertujuan meyakinkan partisipan agar tertarik dengan tawaran yang dimaksud. Dikarenakan toko tersebut masih dalam keadaan sepi responden berusaha menarik perhatian partisipan untuk mampir mengunjungi lokasi penjualan karena pada saat itu responden baru saja memulai kegiatan penjualan. Teknik ganjaran(payoff technique) juga ditemukan dalam ujaran "oh, untuk undian luckydraw diundi di akhir Desember, dengan total hadiah ada banyak banget sampai sepuluh juta rupiah dan voucher undiannya itu diundi setiap hari dengan total hadiahnya banyak banget. Ada parcel sembako, dan aksesoris hand phone. Jadi, buruan langsung ke store kita. Jangan ke store lain. Be cus buruan ya, ditunggu kedatangannya lo." Responden berusaha meyakinkankan partisipan dengan cara mengiming-ngimingi hal yang menguntungkan dan menjanjikan suatu harapan agar partisipan tertarik dengan apa yang disampaikan.

Nama Toko : Warung Serbu

Hari/ Tanggal : Rabu, 16 Desember 2020

Pukul : 20:23 WIB

\section{Bentuk Persuasif}

Pembeli

: "ada tempe?."

Penjual : "ada, mau yang mana? Yang masak, yang mentah. yang ini satu dua ribu, lima ribu tiga, ini yang satu seribu, lima ribu enam. Mau yang mana?."

Pembeli : "kalau yang kecilnya lagi gak ada bang?."

Penjual : "ada, ini satu delapan ratus. Terserah mau yang mana pilih aja. Mau beli berapa emangnya?." 


$$
\begin{array}{ll}
\text { Pembeli } & \text { : “ini berapa bang?." } \\
\text { Penjual } & \begin{array}{l}
\text { : "delapan ratus, kalau mau } \\
\text { banyak dikasih diskon." }
\end{array} \\
\text { Pembeli } & \begin{array}{l}
\text { : "dahlah bang, yang ini aja. } \\
\text { Kalau ima ribu berapa?." }
\end{array} \\
\text { Penjual } & \text { : "enam." } \\
\text { Pembeli } & \text { : "itu gak bisa nambah lagi?." } \\
\text { Penjual } & \text { :"bisa, nambah doa." } \\
\text { Penjual } & \text { : "iya." }
\end{array}
$$

Persuasif pada iklan promosi di Kota Perbaungan dilihat dari teknik-teknik komunikasi persuasif menggunakan teknik ganjaran(payoff technique) dalam ujaran "ada, mau yang mana? Yang masak, yang mentah. Yang ini satu dua ribu, lima ribu tiga, ini yang satu seribu, lima ribu enam. Mau yang mana?." Responden berusaha meyakinkan partisipan dengan cara mengiming-ngimingi hal yang menguntungkan agar partisipan tertarik untuk membelinya.

Nama Toko : Pajak Niza

Hari/ Tanggal : Senin, 14 Desember 2020

Pukul

$$
\text { : 13:31 WIB }
$$

\section{Bentuk Persuasif}

Penjual: "singgah kak, cari apa kak $e . "$

Pembeli : "cari jam kak."

Penjual: "jam yang mana?."

Pembeli : "coba lihat yang ini kak."

Penjual: "yang ini?."

Pembeli : "ini, kalau dipotong bisa kak?."

Penjual: "bisa, kita lagi ada promo loh kak.

Beli dua gratis satu."

Pembeli : "gratisannya yang mana

kak?."

Penjual: "gratisannya kakak mau yang mana?."

Pembeli : "kacamata bisa kak?",

Penjual: "bisa."

Pembeli : "berapa kak?."

Penjual: "ini, tujuh lima."

Pembeli : "bisa kuranglah."

Penjual: "bisa kurang sikit. Jam cowoknya gak sekalian?.”

Pembeli : "gak ah."
Penjual: "jam cowoknya ada tuh yang couple, murah aja loh kak $e$. yang ini aja?."

Persuasif pada iklan promosi di Kota Perbaungan dilihat dari teknik-teknik komunikasi persuasif menggunakan teknik ganjaran (payoff technique) dalam ujaran "bisa, kita lagi ada promo loh kak. Beli dua gratis satu." Responden berharap agar partisipan membeli barang dagangannya dengan memperoleh keuntungan dari barang tersebut. Teknik tataan (icing technique) juga ditemukan dalam ujaran "jam cowoknya ada tuh yang couple, murah aja loh kak $e$. Yang ini aja?." Responden berusaha menawarkan barang dagangannya dengan mengimingngimingkan harga yang murah kepada partisipan agar tertarik untuk dibeli.

Nama Toko : Sotang Kita

Hari/ Tanggal : Rabu, 16 Desember 2020

Pukul : 21:28 WIB

\section{Bentuk Persuasif}

Penjual: "selamat datang bang di sotang kita. Singgah, mau pesan apa bang?."

Pembeli : "yang ini bang."

Penjual: "beli dua dapat gratisannya satu bang, karena kita lagi bang." promo sampe akhir tahun ini

Pembeli : "yaudah beli dua, yang ini." Penjual: "ini bang, yaudah bentar bang. Ini bang, ini gratisannya bang ya."

Pembeli : "berapa bang?."

Penjual: "lima belas bang, makasih ya."

Persuasif pada iklan promosi di Kota Perbaungan dilihat dari teknik-teknik komunikasi persuasif menggunakan teknik ganjaran (payoff technique) dalam ujaran "beli dua dapat gratisannya satu bang." 
Responden berusaha mengiming-ngimingkan hal yang menguntungkan atau yang menjanjikan harapan sehingga pembeli tertarik untuk membelinya. Teknik tataan (icing technique) dalam ujaran "karena kita lagi promo sampe akhir tahun ini bang." Ujaran responden mengandung makna yang berusaha meyakinkan partisipan dikarenakan promosi hanya berlaku dengan waktu tyang sudah ditentukan.

Nama Toko : @momkiee

Hari /Tanggal : Senin, 16 November 2020

Pukul : 20:17 WIB

\section{Bentuk Persuasif}

$\begin{array}{ll}\text { @momkiee } & \text { :"Ini warna } \\ & \text { lemonnya. Ni } \\ & \text { aslinya warnanya } \\ & \text { lemonya sayang ya, } \\ & \text { warna aslinya tu } \\ & \text { warna lemon." } \\ \text { @momkiee } & \text { : "size apa beb." } \\ & \text { "kak Evi, kak Evi fix } \\ & \text { kan dulu ni kak evi } \\ & \text { kucen tolonglah } \\ & \text { kakak fix kan ini } \\ & \text { seratus empat puluh } \\ & \text { ribu aja. Yok kak, di } \\ & \text { fix kan kak Evi } \\ & \text { kucen seratus empat } \\ & \text { puluh ribu aja. } \\ & \text { Cantik, oke. Baju } \\ & \text { ini seratus empat } \\ & \text { puluh ribu, satu dua } \\ & \text { tiga sold out. Next, } \\ \text { ada kemeja cantik } & \text { seratus empat puluh } \\ \text { lima ribu. Oh ini } \\ \text { motifnya cantik } \\ \text { banget guys. Ini aku } \\ \text { pake dulu biar aku } \\ \text { tau muat sampai } \\ \text { BB berapa ya. Ini } \\ \text { seratus empat puluh } \\ \text { lima ribu ya guys } \\ \text { ya. Ada empat } \\ \text { warna nih seratus } \\ \text { empat puluh lima } \\ \text { ribu, cantik }\end{array}$

bangetkan?.

Warnanya ada warna apa aja? Ada warna hijau, ada warna putih, warna navy, yang Nisa pakai ada warna hitam. Nih hitamnya ya guys ya, cantik banget ini kemejanya benerbener ini secantik ini ya sayang ya. Only seratus berapa tadi ya, seratus empat puluh lima ribu. Ni muat sampe BB tujuh lima ya, kita free ongkir seluruh Indonesia sayang.

@ Viesumanti02 : " $f$ hitam.” 06

@momkiee@ “oke, aku mau pakai yang warna navy nya boleh dong ya."

@Eviavievi : "fix hijau."

@momkiee "oke, kak Evi ni suka kalihijo lo. Terus yang mau navy nya Nisa coba warna navy nya ya guys. Fix biru dongker oke, oke biru dongkernya langsung di inbox ya."

@Melly.harianto : "fix putihla sa."

@momkiee : "fix kemeja cantik ini, satu dua tiga guys. Sold out.

Persuasif pada iklan promosi di Kota Perbaungan dilihat dari teknik-teknik 
komunikasi persuasif menggunakan teknik tataan (icing technique) dalam ujaran "kak Evi, kak Evi fix kan dulu ni kak evi kucen tolonglah kakak fix kan ini seratus empat puluh ribu aja. Yok kak, di fix kan kak Evi kucen seratus empat puluh ribu aja. Cantik, oke. Baju ini seratus empat puluh ribu, satu dua tiga sold out." Responden berusaha menarik perhatian partisipan dengan cara menggugah hati nurani partisipan dengan mengubah pesan berupa perintah, anjuran maupun teguran dari responden agar partisipan bertindak sesuai dengan pesan yang diharapkan. Responden mengucapkan dengan nada suara yang lembut dan menggunakan ekspresi wajah yang memelas untuk merayu partisipan. Teknik ganjaran (payoff technique) dalam ujaran "kita free ongkir seluruh Indonesia sayang." Responden berusaha mengiming-ngimingkan suatu hal yang menguntungkan dengan menjanjikan gratis pengiriman seluruh Indonesia kepada partisipan dengan tujuan agar partisipan tertarik untuk membeli barang dagangannya.

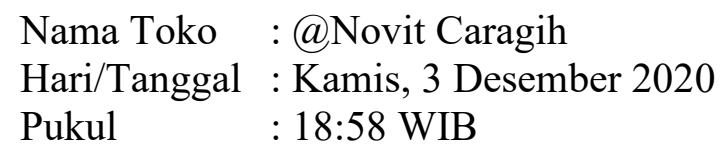

\section{Bentuk Persuasif}

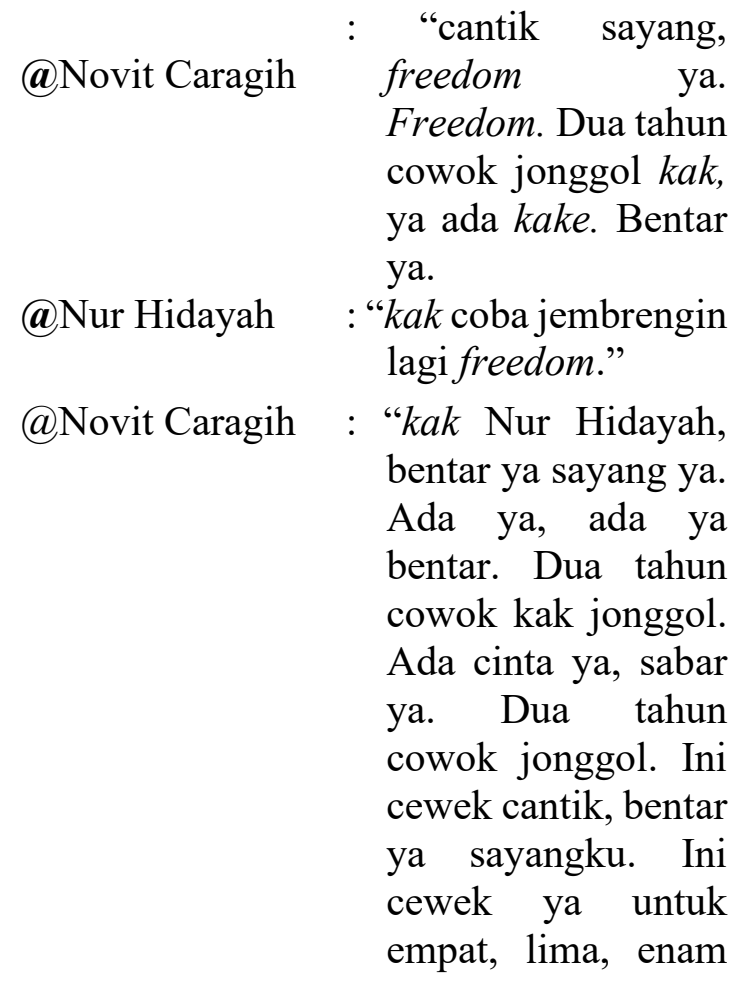

tahun bisa pake cewek ni. Cewek ya, cewek ini oke. Kalau mau ini fix tebal, fix tebal empat puluh, fix tebal empat puluh, tebal empat puluh, empat, lima, enam tahun ya. Fix liris merah, fix liris merah empat puluh, fix liris merah empat puluh, fix liris merah empat puluh, lima, enam, tujuh tahun ya, fix pink, fix pink empat puluh, fix pink empat puluh ya, empat, lima, enam tahun. Empat, lima, enam tahun. Fix micky, fix micky ya empat puluh cowok. Empat, lima tahun ini uniqlo ya kak e. Uniqlo hijau empat puluh, uniqlo hijau untuk empat, lima tahun bisa pake. Ini cantik, lima, enam, tujuh tahun. Lima, enam, tujuh tahun ya. Fix baru, fix baru empat puluh, fix baru empat puluh. Bantu tes, bantu up-nya yok, bantu tes, bantu up, bantu share, fix baru empat puluh, oke.

$@$ Marwin S. : "gap abu-abu bisa Gultom empat puluh kak?."

@Novit caragih : "Yuk bantu share-nya lagi, bantu up, bantu tesnya $y u k$ biar kita jembrengin lagi $y u k$. Kita jembrengin lagi, ini pun cantik 
kak. Enam, tujuh, delapan tahun bisa pake. Enam, tujuh, delapan tahun ya bisa pake. Kalau mau ini fix original brandid casual.Fix original ya, enam, tujuh, delapan tahun."

Persuasif pada iklan promosi di Kota Perbaungan dilihat dari teknik-teknik komunikasi persuasif menggunakan teknik tataan (icing technique) dalam ujaran "yuk bantu share-nya lagi, bantu up, bantu tesnya yuk biar kita jembrengin lagi yuk. Kita jembrengin lagi, ini pun cantik kak. Enam, tujuh, delapan tahun bisa pake. Enam, tujuh, delapan tahun ya bisa pake. Kalau mau ini fix original brandid casual.Fix original ya, enam, tujuh, delapan tahun. Responden berusaha membujuk partisipan agar mau melakukan hal yang diminta dengan menjanjikan suatu hal yang dapat diterima oleh partisipan.

Nama Toko : @Novita Sari

Hari/Tanggal : Minggu, 29 November 2020

Pukul : 21:04 WIB

\section{Bentuk Persuasif}

@Novita Sari : "jadi yang pertama ini dulu ya yang gamis sale ini, LD-nya seratus dua puluh ya bun ya yang semalam ya bun. Ini LDnya seratus dua puluh ya free belt ini harganya cuma seratus sepuluh ribu bunda. Jadi, ini stoknya sangat-sangat menipis bunda jadi harus gercep semalam banyak kali bunda-bunda yang order baju ini ya bun, karena bahannya bagus ya bun bahan import dan udah free belt dan LDnya itu besar bunda. Jadi, untuk BB tujuh puluh kilo itu masih muat ya bunda karena LD-nya seratus dua puluh bunda. Terima kasih kepada bunda Uci dan bunda Rosa telah mengikuti siaran langsug ini. Gercep ya, ini di sale ya bun ya harganya seratus sepuluh ribu aja bunda udahfree belt bunda. Jadi kerahnya ini bun bisa kek gini ya bun sepatu ya bun ya kalo kita berhijab mau kita ginikan jilbabnya ya bun kita bisa pake gini bun. Ini bisa dikancing bunda, jadi cakep bangetkan bun?. Nah yang kedua ini ya bun ini gamis sale yang kedua ya bun. Nah, cara order-nya bunda bisa SS baju yang Novi jembrengin ya bun ya dan dikirim ke WA yang ada di bio tapi jangan di-call ya bun. Nanti Novi balas setelah siaran langsung ini berakhir ya bunda. Nah, jadi ini harganya cuma seratus sepuluh ribu bunda ini bahannya ditengok bun bagus bangetkan bun. Jadi, ini memang barang import iya bun ya barang import bangkok. Ini udah ada free belt-nya bun, ini free belt ya ini warna putih, pink ya bun ya. ini ya bun ya ini cuma seratus sepuluh ribu aja bunda. Jadi, kalo mau gercep ya bun ya seratus sepuluh ribu kita sale bunda ini yang barang sale kedua bun ini memang stoknya tinggal sangat-sangat 
sedikit bun. Jadi, yang mau gercep ya bun ya ini LD seratus. Ini LD-nya seratus ya bunda ya. jadi, gercep ya bun, yang mau gercep ya bunda ya.

\begin{tabular}{|c|c|}
\hline @Nurainun & : "tes." \\
\hline Hutasuhut Inun & \\
\hline @Jenika & : "yang kayak kakak \\
\hline Anjela Sary & $\begin{array}{l}\text { pakai ada LD seratus } \\
\text { dua puluh kak." }\end{array}$ \\
\hline @Uchie Tw & $\begin{array}{l}\text { : "yang Novi pake ada } \\
\text { gak LD seratus dua } \\
\text { puluh." }\end{array}$ \\
\hline
\end{tabular}

Persuasif pada iklan promosi di Kota Perbaungan dilihat dari teknik-teknik komunikasi persuasif menggunakan teknik ganjaran (payoff technique) dalam ujaran "jadi yang pertama ini dulu ya yang gamis sale ini, LD-nya seratus dua puluh ya bun ya yang semalam ya bun. Ini LD-nya seratus dua puluh ya free belt ini harganya cuma seratus sepuluh ribu bunda. Jadi, ini stoknya sangatsangat menipis bunda jadi harus gercep semalam banyak kali bunda-bunda yang order baju ini ya bun, karena bahannya bagus ya bun bahan import dan udah free belt dan LD-nya itu besar bunda." Responden berusaha mengiming-ngimingi partisipan dengan hal yang menguntungkan dan menjanjikan agar partisipan tertarik dengan pesan komunikasi yang disampaikan. Teknik tataan (icing technique)terdapat dalam dua ujaran responden "(1)Gercep ya, ini di sale ya bun ya harganya seratus sepuluh ribu aja bunda udah free belt bunda. Jadi kerahnya ini bun bisa kek gini ya bun sepatu ya bun ya kalo kita berhijab mau kita ginikan jilbabnya ya bun kita bisa pake gini bun. Ini bisa dikancing bunda, jadi cakep bangetkan bun?." (2)Nah, jadi ini harganya cuma seratus sepuluh ribu bunda ini bahannya ditengok bun bagus bangetkan bun. Jadi, ini memang barang import iya bun ya barang import bangkok. Ini udah ada free belt-nya bun, ini free belt ya ini warna putih, pink ya bun ya. ini ya bun ya ini cuma seratus sepuluh ribu aja bunda. Jadi, kalo mau gercep ya bun ya seratus sepuluh ribu kita sale bunda ini yang barang sale kedua bun ini memang stoknya tinggal sangat-sangat sedikit bun. Jadi, yang mau gercep ya bun ya ini LD seratus. Ini LD-nya seratus ya bunda ya. jadi, gercep ya bun, yang mau gercep ya bunda ya." Responden berusaha menata pesan komunikasi dengan imbauan emosional yang sedemikian rupa agar partisipan tertarik perhatiannya.

Nama Toko : @Ayu Handayani

Hari/Tanggal : Sabtu, 5 Desember 2020

Pukul : 14:23 WIB

\section{Bentuk Persuasif}

@,Ayu Handayani : “yuk, kita mulai ya."

@imey

: "jaket jeans hoodie LD awal seratus dua puluh ada kak?."

@Ayu Handayani : “hoodie gak ada, kita mulai ya ini blezer ya LD-nya ini untuk pemakaian sembilan delapan, sembilan lima mentoknya sembilan delapan ya blezer. Terus ada ininya ya, ini LD sembilan lima, sembilan delapan mentoknya sembilan delapan ya. ini saya LD seratus masuk. Kalau mau ini ya CIN ya lima puluh aja ya ambek tiga bisa korting ya. kalau mau ini CINfix sebutkan clue nomorWA ya, sebutkan clue dan nomor WA. Kalau mau ini ya CIN, 
@Imey

clue-nya CIN
harganya lima
puluh $K$ ya
sertakan nomor
WA-nya. Ini
pemakaian cowok
ya dia hijaunya
hijau army ya
tangannya seperti
ini LD-nya ini
untuk LD seratus
lima belas ya
mentoknya ini
pemakaian cowok
ya brand-nya kalau
mau ini fix hijau
army ya fix hijau
army terakan
nomor WA ya. Fix
hijau army lima
puluh ya. kak, mau
ini? Untuk cowok
yang ada kak cuma
ini ya kak ada
minus-nya.

: "cewek kak."

@,Ayu Handayani : " $g a k$ ada cewek kak.

$K a k$, ini mau kak cewek cowoklah pemakaiannya. Ini ya kak Imey ini LD mentoknya seratus ya. Mau ini kak? Kita kasih lima puluh ya ini brandnya. Kalau mau fix litle lima puluh $K$ ya hoodie ya kak ya.

: “ada LD seratus dua

@Nur Hidayah puluh kak?."

@Ayu Handayani :“ada bang, ada. Kak ini pemakaian cewek ya cakep ya ni ya ini LD-nya sembilan delapan ya LD-nya

pemakian cewek

ya, mentoknya sembilan delapan ya kak. Ini model krep ya, berkantong ya kak. Kalau mau ini ya brand-nya ini ISCIS siosio."

@ Rinto Fahry

:"max LD berapa yang bertopi tadi? Cowok atau cewek?."

@,Ayu Handayani : “ cewek, cowok ya masuk ya bang Rinto. Ini kak untuk cewek ya, ini LD gedek nya tadi minta berapa? LD mentoknya seratus ya ini tangannya seperti ini ya lipat."

: "fix bertopi."

@ Rinto Fahry

@,Ayu Handayani : "oke bang, kak ini LD-nya seratus delapan belas tapi dia ngestritkak, mau kak?susah lo cari LD gedek. LD aku sembilan enam, seratus tergantung. Oke ya bang Rinto ya. mau ini? Ini LDnya bisa ni kek nya sama kakak ngaret. Susah kak cari LD gedek kak, makasih ya bang Rinto.

Persuasif pada iklan promosi di Kota Perbaungan dilihat dari teknik-teknik komunikasi persuasif menggunakan teknik ganjaran (payoff technique) dalam ujaran 
"Terus ada ininya ya, ini LD sembilan lima, sembilan delapan mentoknya sembilan delapan ya. ini saya LD seratus masuk. Kalau mau ini ya $C I N$ ya lima puluh aja ya ambek tiga bisa korting ya. kalau mau ini CINfix sebutkan clue nomorWA ya, sebutkan clue dan nomor WA. Kalau mau ini ya CIN, cluenya $C I N$ harganya lima puluh $K$ ya sertakan nomor WA-nya." Pesan komunikasi responden mengandung makna ajakan yang mengiming-ngimingkan hal yang menguntungkan dan menjanjikan agar partisipan mau membeli dengan jumlah yang banyak. Teknik tataan (icing technique) terdapat dalam ujaran" kak ini LD-nya seratus delapan belas tapi dia ngestrit kak, mau kak?susah lo cari LD gedek. LD aku sembilan enam, seratus tergantung. Oke ya bang Rinto ya. mau ini? Ini LD-nya bisa ni kek nya sama kakak ngaret. Susah kak cari LD gedek kak, makasih ya bang Rinto." Responden berusaha menata pesan komunikasi dengan sedemikian rupa melalui imbauan emosional agar partisipan dapat terpengaruh dengan ajakannya.

1) Nama Toko:@Liakando Sianturi

Hari/Tanggal : Rabu, 16 Desember 2020

Pukul : 12:54 WIB

\section{Bentuk Persuasif}

(a)Liakando : "ada momci Kori, Sianturi toples ungunya berapa harganya $k a k$ ? Yang persegi ini kak? Toples ungu ada ini warna pushi ya. ini, ini harga normalnya seratus sembilan puluh kalau beli dua saya kasih diskon khusus hari ini dua, seratus dua puluh aja, seratus dua puluh aja

@Khansa : "gelas merah yang di Thalita atas berapa kak?."
(a)Liakando : "kalau mau ini clueSianturi nya fix toples pushi ya seratus dua puluh ya bunda momci Kori. Gelas merah yang di atas berapa kak?. Ini gelas merahnya harga normalnya dua ratus khusus hari ini saya kasih seratus dua puluh dapat empat. Seratus dua puluh dapat empat cluenya gelas merah seratus dua puluh dapat dapat apa ya kakak, seratus dua puluh dapat empat. Kalau mau fix gelas merah ini kapasitasnya empat ratus mili, ini ya kapasitasnya empat ratus mili. Kalau mau fix gelas merah seratus dua puluh cantumkan nomor WA. Ini yang udah tes, up ada hadiahnya ya kalau nonton sampai akhir live hadiahnya kita kasih tapi dikasih dicantumkan nomor WA ya contoh up cantumkan nomor WA. Jadi, nanti kita kasih hadiahnya."

Persuasif pada iklan promosi di Kota Perbaungan dilihat dari teknik-teknik komunikasi persuasif menggunakan teknik ganjaran (payoff technique) dalam dua ujaran responden (1)"ini harga normalnya seratus sembilan puluh kalau beli dua saya kasih diskon khusus hari ini dua, seratus dua puluh aja, seratus dua puluh aja. (2)" Ini gelas merahnya harga normalnya dua ratus khusus 
hari ini saya kasih seratus dua puluh dapat empat. Seratus dua puluh dapat empat cluenya gelas merah seratus dua puluh dapat dapat apa ya kakak, seratus dua puluh dapat empat." Responden berusaha meyakinkan partisipan dengan bujukan mendapatkan suatu hal yang menguntungkan, sehingga partisipan harus membeli barang dangannya dengan jumlah banyak untuk mendapatkan harga murah. Teknik tataan (icing technique) juga ditemukan dalam ujaran "Ini yang udah tes, up ada hadiahnya ya kalau nonton sampai akhir live hadiahnya kita kasih tapi dikasih dicantumkan nomor WA ya contoh up cantumkan nomor WA. Jadi, nanti kita kasih hadiahnya." Responden berusaha menarik perhatian partisipan dengan imbauan emosional agar partisipan bersedia hadir dan menonton live hingga selesai.

2) Nama Toko:@Nurhenni Sembiring Hari/Tanggal : Jumat, 4 Desember 2020

Pukul

$$
\text { : 13:37 WIB }
$$

\section{Bentuk Persuasif}

@ Nurhenni

Sembiring

$\begin{array}{ll}\text { @Elvi Ginting } & \text { : “cardigan ada kak?." } \\ \begin{array}{ll}\text { @Nurhenni } & \text { : “cardigangak ada, fix } \\ \text { Sembiring } & \text { coklat ya, fix coklat. } \\ & \text { Rok cel ya?." }\end{array}\end{array}$

@Dories : "fix coklat."

Ayuastuti

@Rise Iche : "panjang $m b k$ ?.”

"bordir dada, ini ya kak e. Nih,size-nya size tiga dua, tiga tiga. Fix coklat, fix coklat ya tiga dua-tiga-tiga., fix coklat tiga duatiga-tiga, , fix coklat ya."

\section{Rok cel ya?."}

@Nurhenni
Sembiring

Sembiring 


\section{Bentuk Persuasif}

@Ifradiah : “ayok bang kakak-kakak Diah yang mau suaminya nampak cakep ini untuk LD seratus, seratus lima ya kak cowok ya. pemakaian cowok ya ini cakep kak dia model scrub ya kak ya atau sampai pinggang tergantung tinggi badannya. Kalo mau ini LD seratus sepuluh, seratus ya kak ya mentoknya. Kalau mau ini scan ya kak ya fix scan delapan puluh lima ribu aja ya kak. Kalau mau fix scan delapan puluh lima ribu terakan nomor WA ya kak ya. ini pemakain cewek ya kak ini model scrub ya kak ya ada karetkaretnya gini ya ini ya cakepbanget ini kak. Ini ada seperti ini ya kak ya ini belakangnya kek gini $k a k$, ini cakep banget ini kak ini lengannya tangannya jeans kek gini ya kak ya ada jipernya ya kak ya jiper ditangannya ya bisa bongkar pasang jipernya kak ini jeans-nya model jiper di depannya kak ya. ini ya kak ini model scrub ya kak ya ini kak cakep ya ada minusnya kotor belum dicuci kak. Kalo mau ini ya kak xoxo fix xoxo harganya lima lima ya kak ya terakan nomor WA yang mau ya kak."

Persuasif pada iklan promosi di Kota Perbaungan dilihat dari teknik-teknik komunikasi persuasif menggunakan teknik tataan (icing technique) dalam ujaran "ayok bang, kakak-kakak yang mau suaminya nampak cakep ini untuk LD seratus, seratus lima ya kak cowok ya. pemakaian cowok ya ini cakep kak dia model scrub ya kak ya atau sampai pinggang tergantung tinggi badannya. Kalo mau ini LD seratus sepuluh, seratus ya kak ya mentoknya. Kalau mau ini scan ya kak ya fix scan delapan puluh lima ribu aja ya kak. Kalau mau fix scan delapan puluh lima ribu terakan nomor WA ya kak ya." responden berusaha menarik perhatian partisipan dengan memberitahukan kualitas barang dagangan yang sesuai untuk digunakan agar partisipan tertarik dengan yang disampaikan.

Berdasarkan hasil analisis dan pendeskripsian data yang telah dilakukan dari empat belas sampel bahasa persuasif pada iklan promosi di Kota Perbaungan ditemukan tiga teknik-teknik Berdasarkan hasil analisis dan pendeskripsian data yang telah dilakukan dari empat belas sampel bahasa persuasif pada iklan promosi di Kota Perbaungan ditemukan tiga teknik-teknik komunikasi persuasif yaitu teknik asosiasi, teknik ganjaran (payoff technique), danteknik tataan (icing technique). Berikut ini dipaparkan teknik-teknik komunikasi persuasif yang ditemukan dalam bahasa persuasif pada iklan promosi di Kota Perbaungan.

1) Teknik Asosiasi

Teknik asosiasi adalah teknik penyajian komunikasi dengan cara menumpangkannya pada suatu objek atau peristiwa yang sedang menarik perhatian orang banyak. Pada bahasa persuasif iklan promosi di Kota Perbaungan dari empat belas sampel ditemukan hanya satu teknik asosiasi yaitu di@Habibie Parfum seperti pada (1) "bentar ya kak, ini orang sering make kak." (2) "itu parfum laundry kak. Ambillah kak, untuk gosok." (3) "yang merah sih biasanya, ambillah kak satu sepuluh ribunya kak."Teknik asosiasi bertujuan memberikan suatu dasar kebenaran terhadap apa yang disampaikan berdasarkan keinginan dan kepercayaan kepada partisipan. Teknik asosiasi yang digunakan dalam komunikasi bahasa 
persuasif pada iklan promosi di Kota Perbaungan memberikan informasi sekaligus mempengaruhi partisipan. Teknik ini juga digunakan agar partisipan tidak cepat bosan dan pergi meninggalkan lokasi penjualan.

\section{2) Teknik Ganjaran (payoff technique)}

Teknik ganjaran (payoff technique) adalah teknik penyajian komunikasi dengan cara mengiming-ngimingkan hal yang menguntungkan atau hal yang menjanjikan. Pada bahasa persuasif iklan promosi di Kota Perbaungan dari empat belas sampel ditemukan sebelas sampel teknik ganjaran (payoff technique) (1) sahabat ponsel, (2) Habibie Parfum, (3) My Poot Street Food, (4) Bintang Ponsel, (5) warung serbu, (6) pajak Niza, (7) sotang kita, (8)@momkiee, (9) Novita Sari, (10) Ayu Handayani, (11) Liakando Sianturi. Teknik ganjaran (payoff technique)bahasa persuasif pada iklan promosi di Kota Perbaungan seperti“oh, untuk undian luckydraw diundi di akhir Desember, dengan total hadiah ada banyak banget sampai sepuluh juta rupiah dan voucherundiannya itu diundi setiap hari dengan total hadiahnya banyak banget. Ada parcel sembako, dan aksesoris hand phone. Jadi, buruan langsung ke store kita. Jangan ke store lain. Be cus buruan ya, ditunggu kedatangannya lo." Teknik persuasif ganjaran (payoff technique) yang digunakandalam komunikasi pada iklan promosi di Kota Perbaungan bertujuan mempengaruhi partisipan dengan cara mengiming-mengimingkan hal yang menguntungkan atau hal yang menjanjikan harapan. Dalam rangka mencapai tujuannya, komunikasi bahasa persuasif pada iklan promosi menggunakan teknik ganjaran ini sebagai upaya untuk menumbuhkan kegairahan emosional dalam diri seorang partisipan. Teknik ini menyajikan pesan komunikasi yang mengandung anjuran, hasilnya akan memuaskan apabila ditaati. Komunikasi bahasa persuasif pada iklan promosi di Kota Perbaungan juga menggunakan teknik ini untuk mempengaruhi partisipan agar mau membeli barang dagangannya.

\section{3) Teknik Tataan (icing technique)}

Teknik tataan (icing technique)adalah teknik penyajian persuasif menata pesan dengan imbauan emosional (emotional appeal) sedemikian rupa, sehingga partisipan menjadi tertarik perhatiannya. Pada bahasa persuasif iklan promosi di Kota Perbaungan dari empat belas sampel ditemukan tiga belas sampel teknik tataan (icing technique)(1) sahabat ponsel, (2) Habibie Parfum, (3) My Poot Street Food, (4) Bintang Ponsel, (5) @Novit Caragih, (6) pajak Niza, (7) sotang kita, (8)@momkiee, (9)@Novita Sari, (10) @Ayu Handayani, (11)@Liakando Sianturi, (12)@Nurhenni Sembiring, (13)@Ifradiah Diah. Teknik tataan (icing technique) bahasa persuasif pada iklan promosi di Kota Perbaungan seperti "Yuk bantu share-nya lagi, bantu up, bantu tesnya yuk biar kita jembrengin lagi yuk. Kita jembrengin lagi, ini pun cantik kak. Enam, tujuh, delapan tahun bisa pake. Enam, tujuh, delapan tahun ya bisa pake. Kalau mau ini fix original brandid casual.Fix original ya, enam, tujuh, delapan tahun." Teknik tataan (icing technique)bertujuan mempengaruhi partisipan dengan cara menata pesan komunikasi dengan semenarik mungkin. Pada dasarnya teknik ini bertujuan menggugah hati nurani partisipan dengan mengubah pesan berupa perintah, anjuran, atau teguran dari responden. Hal ini dilakukan pada komunikator iklan promosi agar partisipan merasa tertarik dan akhirnya bertindak sesuai dengan pesan yang disampaikan. Responden iklan promosi di Kota Perbaungan juga menggunakan teknik tataan untuk membujuk partisipan agar mau membeli barang dagangannya.

\section{Simpulan dan Saran}

Berdasarkan hasil pembahasan tentang bahasa persuasif pada iklan promosi di Kota Perbaungan yang telah diuraikan dapat disimpulkan bahwa terdapat empat belas sampel yang diperoleh dari peneliti yaitu (1) 
sahabat ponsel, (2) Habibie Parfum, (3) My Poot Street Food, (4) Bintang Ponsel, (5) @ Novit Caragih, (6) pajak Niza, (7) sotang kita, (8)@momkiee, (9)@Novita Sari, (10) @Ayu Handayani, (11)@Liakando Sianturi, (12)@Nurhenni Sembiring, (13)@Ifradiah Diah dan (14) warung serbu. Teknik-teknik komunikasi persuasif yang digunakan sebanyak tiga teknik, yaitu (1) teknik asosiasi, (2) teknik ganjaran (payoff technique) dan (3) teknik tataan (icing technique).

Hasil penelitian menunjukkan bahwa teknik persuasif yang paling dominan digunakan oleh iklan promosi di Kota Perbaungan adalah teknik tataan (icing technique). Teknik tersebut digunakan oleh iklan promosi untuk menarik minat partisipan terhadap produk yang ditawarkan. Selanjutnya, teknik persuasif yang tidak dijumpai dalam bahasa persuasif pada iklan promosi di Kota Perbaungan meliputi: teknik integrasi dan teknik red-herring. 


\section{Daftar Referensi}

Astuti, Sri Puji. 2017. “Persuasi dalam Wacana Iklan.” NUSA, Vol.12, No.1 Februari.

Azwardi. 2018. Metode Penelitian Pendidikan dan Sastra Indonesia. Banda Aceh: Syiah Kuala University Press.

Damayanti, Rini. 2016. "hiperealitas wacana persuasi iklan kartu telepon seluler." Jurnal Buana Bastra. Tahun 3, No. 1 april.

Departemen Pendidikan Nasional. 2012. Kamus Besar Bahasa Indonesia Cetakan Ketiga Edisi IV. Jakarta: PT Gramedia Pustaka Utama.

Harista, Eva. 2017. "Penggunaan Bahasa Persuasi di Media Social dalam Berdakwah Pada Akun Facebook'yusuf Mansur (Official)." Jurnal Dakwah dan Pengembangan Sosial Kemanusiaan, Vol.8, No.2 (2017), pp. 308-324.

Moleong, 2017. Metodologi Penelitian Kualitatif. Bandung: PT REMAJA ROSDAKARYA.

Syamsurizal. 2016. "Strategi Komunikasi Persuasif Dalam Aktivitas Pemasaran." Jurnal Lentera Bisnis, Vol.5,No.2 November 2016/ISSN2252-9993.

Wati, Fadillah Fidyah. 2017. "Kemampuan Komunikasi Persuasif Pengelola Museum Provinsi Sulawesi Tengah.” Jurnal Online Kinesik, Vol.4, No. 1 April 2017. 